$8-17-2021$

Discrepancy between PCR based SARS-CoV-2 tests suggests the need to re-evaluate diagnostic assays

Zain Mushtaq

Sadia Shakoor

Akber Kanji

Najma Shaheen

Asghar Nasir

See next page for additional authors

Follow this and additional works at: https://ecommons.aku.edu/pakistan_fhs_mc_med_intern_med

Digipalrt of the Internal Medicine Commons, Life Sciences Commons, Pathology Commons, and the Virus Grexereas ommons

Network

Logo 


\section{Authors}

Zain Mushtaq, Sadia Shakoor, Akber Kanji, Najma Shaheen, Asghar Nasir, Zeeshan Ansar Ahmed, Imran Ahmed, Syed Faisal Mahmood, Rumina Hasan, and Zahra Hasan 


\title{
Discrepancy between PCR based SARS-CoV-2 tests suggests the need to re-evaluate diagnostic assays
}

\author{
Muhammad Zain Mushtaq ${ }^{1}$, Sadia Shakoor ${ }^{2,3}$, Akbar Kanji², Najma Shaheen², Asghar Nasir², Zeeshan Ansar², \\ Imran Ahmed ${ }^{2}$, Syed Faisal Mahmood ${ }^{1}$, Rumina Hasan ${ }^{2}$ and Zahra Hasan ${ }^{2 *}$ (i)
}

\begin{abstract}
Objective: We investigated the discrepancy between clinical and PCR-based diagnosis of COVID-19. We compared results of ten patients with mild to severe COVID-19. Respiratory samples from all cases were tested on the Roche SARS-CoV-2 (Cobas) assay, Filmarray RP2.1 (bioMereiux) and TaqPath ${ }^{\mathrm{TM}}$ COVID19 (Thermofisher) PCR assays.

Results: Laboratory records of ten patients with mild to severe COVID-19 were examined. Initially, respiratory samples from the patients were tested as negative on the SARS-CoV-2 Roche ${ }^{\circledR}$ assay. Further investigation using the BIOFIRE ${ }^{\circledR}$ Filmarray RP2.1 assay identified SARS-CoV-2 as the pathogen in all ten cases. To investigate possible discrepancies between PCR assays, additional testing was conducted using the TaqPath ${ }^{\mathrm{TM}}$ COVID19 PCR. Eight of ten samples were positive for SARS-CoV-2 on the TaqPath assay. Further, Spike gene target failures (SGTF) were identified in three of these eight cases. Discrepancy between the three PCR assays could be due to variation in PCR efficiencies of the amplification reactions or, variation at primer binding sites. Strains with SGTF indicate the presence of new SARSCoV-2 variant strains. Regular modification of gene targets in diagnostic assays may be necessary to maintain robustness and accuracy of SARS-CoV-2 diagnostic assays to avoid reduced case detection, under-surveillance, and missed opportunities for control.
\end{abstract}

Keywords: SARS-COV-2, PCR, COVID-19, Spike gene

\section{Introduction}

Robust diagnostic testing for SARS-CoV-2 is integral to disease surveillance and control of COVID-19. Reversetranscription polymerase chain reaction (RT-PCR) based assays are the most widely used assay to detect RNA viruses. Selection of target genes for diagnostic assays is critical and most diagnostic assays in use include two or more gene targets to maximize diagnostic accuracy (sensitivity and specificity) [1].

\footnotetext{
*Correspondence: zahra.hasan@aku.edu

${ }^{2}$ Department of Pathology and Laboratory Medicine, Aga Khan

University, Karachi, Pakistan

Full list of author information is available at the end of the article
}

SARS-CoV-2 was identified in December 2019 as a beta-coronavirus of the Sarbecovirus family, with a positive-sense RNA genome of $29.9 \mathrm{~kb}$ in size, fourteen open reading frames (orf) encoding accessory nonstructural viral proteins, the nucleocapsid $(\mathrm{N})$, membrane $(\mathrm{M})$, spike (S), and envelope (E) structural proteins [2]. In order for SARS-CoV-2 testing to be reliable, it is necessary that assays that identify viral RNA should be consistent and comparable. When recommendations for SARS-CoV-2 diagnostics were first made, the E gene and RdRp were amongst recommended potential target geness [3]. The $\mathrm{E}$ gene is known to have higher sensitivity while the inclusion of the $\mathrm{N}, \mathrm{S}$, and RNA dependent RNA polymerase $(R d R p)$ genes are recommended for higher specificity [4]. 
No test is $100 \%$ accurate and false-negative results with commercially available diagnostic assays have been documented since the early days of the pandemic [5]. Falsenegative results in the context of symptomatic COVID-19 illness may have several determinants, such as the clinical specimen type (sputum and bronchoalveolar lavage have higher detection rates than nasal and naso- or oropharyngeal specimens) [2], temporal variation in viral shedding [6], as well as diagnostic primer/probe mismatches with infecting SARS-CoV2 virus sequence [7]. However, in the context of increasing reports of SARS$\mathrm{CoV}-2$ variants seeing false negative results in diagnostic tests are of particular concern, as there is a wider implication on misidentification of asymptomatic cases as well, particularly $[8,9]$.

\section{Main text Methods}

Patient specimens were collected from cases admitted into the COVID-19 unit at The Aga Khan University Hospital, Karachi, Pakistan. Inclusion criteria cases were those who had a high clinical suspicion for COVID-19 but had a negative SARS-CoV-2 PCR test conducted at the time of their hospital admission using the SARSCoV-2 Cobas ${ }^{\circledR} 6800$ assay (Roche diagnostics Rotkreuz, Switzerland). The following were considered as signs of COVID-19: classical presentation in terms of signs and symptoms, need for supplemental oxygen support, deranged inflammatory parameters and absence of alternative diagnosis. Exclusion criteria were cases with the abovementioned clinical signs who had an alternative cause for their respiratory illness and those who had a positive SARS-CoV-2 PCR results.

Patients were diagnosed with COVID-19 based on clinical, laboratory and radiological parameters which were used to assess the severity of disease. Clinical parameters included physical signs like tachypnea, tachycardia, hypoxia $\left(\mathrm{SpO}_{2}<94 \%\right.$ at room air), while laboratory investigations included hypoxemia $\left(\mathrm{PaO}_{2}<80 \mathrm{~mm} \mathrm{Hg}\right)$, hyperferritinemia, raised LDH and CRP. Radiologically, patients were assessed on the basis of Computerised tomography $(\mathrm{CT})$ scan or X-ray chest.

COVID-19 severity was assessed on the basis of need for supplemental oxygen support, raised levels of inflammatory markers and more than $50 \%$ involvement of lungs on a CT scan or X-ray chest. Severity was ranked as per the WHO ordinal scale [10]. In each case, nasopharyngeal swab specimens were first tested for SARS-CoV-2 RNA using the SARS-CoV-2 Cobas ${ }^{\circledR}$ (Roche diagnostics Rotkreuz, Switzerland) targeting orf1-ab and E genes. In the case that the SARS-CoV-2 Roche RT-PCR was found to be negative, a second PCR was conducted using the BIOFIRE ${ }^{\circledR}$ Filmarray RP2.1 test (bioMereiux,
Marcy-l'Étoile, France) which includes four bacterial and 18 viral pathogen targets i.e. Adenovirus, influenza $\mathrm{A}$ viruses H1, 2009H1, H3 (FluA-H1, FluA-2009H1, FluA$\mathrm{H} 3$ ), influenza $B$ virus (FluB), parainfluenza virus types 1-4 (Para 1-4), coronaviruses 229E, HKU1, OC43, and NL63 (CoV-HKU1, NL63, 229E, OC43), MERS-CoV (MERS coronavirus), human metapneumovirus (hMPV), Respiratory Syncytial Virus (RSV), human rhinovirus/ enterovirus (Rhino/Entero), Chlamydia pneumoniae, Mycoplasma pneumoniae, Bordetella pertussis, and Bordetella parapertussis in addition to SARS-CoV2 (S and $\mathrm{M}$ gene gene targets). All the RT-PCR assays were conducted at the Aga Khan University, Karachi. SARS-CoV-2 Cobas $^{\circledR}$ and BIOFIRE ${ }^{\circledR}$ Filmarray RP2.1 tests were conducted at the AKUH Clinical Laboratories which are accredited by the College of American Pathologists. For further investigation of discrepancies, a third PCR was conducted using the TaqPath ${ }^{\mathrm{TM}}$ COVID19 (Thermo, Applied Biosystems, USA) assay (S, N and orflab gene targets) at the AKU Research Laboratory. Assay details are provided in Additional file 1.

\section{Results}

We report on ten patients with COVID-19 from Karachi, Pakistan from 18th January to 18th February 2021, presenting to acute care at a tertiary hospital. The patients were investigated for COVID-19 based on their clinical presentation. They were mostly aged $65-74$ years (60\%), followed by two cases aged $>75$ years and two below 54 years of age, Table 1. Patients had between five and forty days of illness with a median period of 8 days. Laboratory parameters found to be raised in all cases were: hyperferritinemia, high biomarker levels (C-reactive protein, D-dimer), details not shown. Chest imaging showed ground-glass opacities or bilateral parenchymal infiltrates, and high population prevalence in all cases. Respiratory samples tested by PCR for SARS-CoV-2 using the SARS-CoV-2 Cobas Roche assay were negative in all cases. Due to a high clinical suspicion for COVID19, samples were further set for testing on the Filmarray RP2.1 platform. In all ten cases, Filmarray results indicated SARS-CoV-2 RNA to be present in the respiratory samples.

To further investigate this, the same ten respiratory specimens tested by Filmarray test were subsequent tested for the presence of SARS-CoV-2 RNA on the TaqPath ${ }^{\mathrm{TM}}$ COVID19 assay. Here we found, eight respiratory specimens to be positive and two were negative (Table 1). All three gene targets in the TaqPath assay (Orf1ab, N and $\mathrm{S})$ were detected in six samples. In one sample $\mathrm{N}$ and $\mathrm{S}$ were detected but Orflab target amplification was absent. $\mathrm{S}$ gene target failure (SGTF) was identified in three specimens. The CT values of gene targets amplified in the 


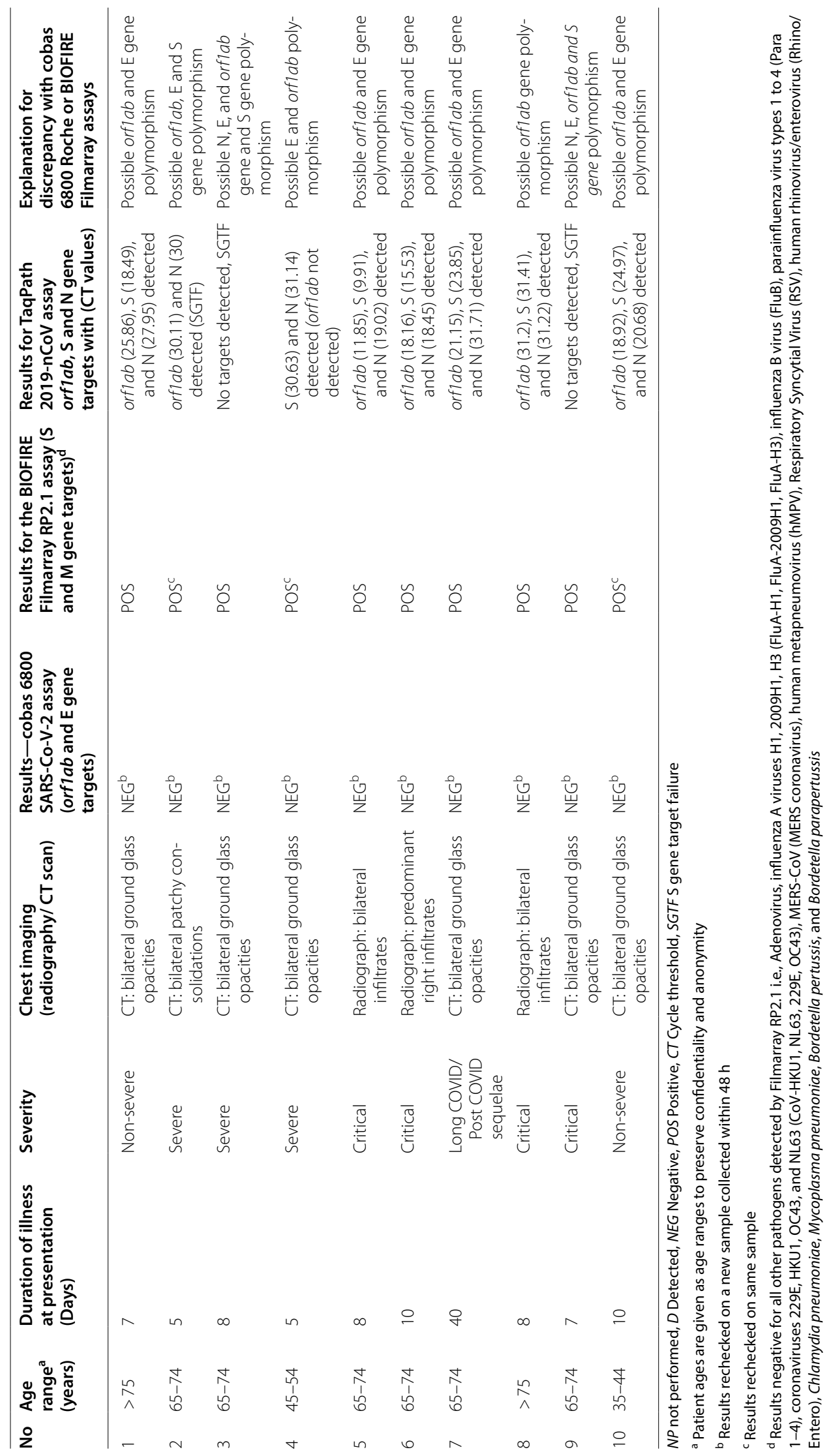


TaqPath assay were CT 31 and below indicating, high to medium viral loads of SARS-CoV-2 [11].

\section{Discussion}

Our data suggest show variations between diagnostic platforms for SARS-CoV-2. A summary of differential commercial RT-PCR test results and possible explanations are given in Table 1 . Single nucleotide mismatch in primer/ probe, especially in the $3^{\prime}$ binding region, may result in failure of target binding and false-negative results [6]. The orflab, $\mathrm{N}$, and $\mathrm{S}$ regions are shown to be the most mutable in SARS-CoV-2, whilst E gene and M gene have been reported to be relatively less error prone [7]. Genomic sequencing would be necessary to further delineate the assumed polymorphisms in SARS-CoV-2 orflab, N, E, and S genes that could result in the discrepancies identified. However, as sequences of target regions in commercial assays are proprietary, a direct comparison between the binding regions of orf1ab in the Roche and TaqPath assays; and of the $\mathrm{S}$ region in the Filmarray and TaqPath assays cannot be made.

The TaqPath COVID19 assay has been used to screen for UK Variant of Concern (B.1.1.7) with SGTF used as a surrogate marker for $\mathrm{H} 69-\mathrm{V} 70$ variant detection [8]. We have limited data on genomic surveillance of SARSCoV-2 in Pakistan however, we have recently identified the introduction of B.1.1.7 lineage strains (unpublished data, sequence submitted). The variability observed in the three cases with $\mathrm{S}$ gene drop-out suggests the presence of new variants. Importantly, given the $\mathrm{CT}$ values of the gene targets detected in each case by the TaqPath assay, the samples had a medium to high viral load. Therefore, it is unlikely that discrepancy between SARS-CoV-2 diagnosis between assays was due to variation between assay sensitivity, further supporting our hypothesis.

These cases we present illustrate the importance of taking into account both the quality of the diagnostic assay and its appropriate design strategy to best capture SARS-CoV-2 strains moving forward. This report is a problem statement and has not made any comparisons or tested any hypotheses. We suggest that the issue of diagnostic test discrepancy be further studied through systematic research. While keeping primer and probe information proprietary is the norm, the medical and research community will benefit from requests from scientists to reveal further information, which is often not made available even upon request [12]. We propose frequent evaluation of national databases of viral genome sequences to inform standards on diagnostic assays. Such an initiative can advise on targets with low mutation frequency, such that $>99 \%$ of circulating variants are detectable using selected primers and probes. Further, in keeping with the rapidly evolving nature of the SARS-CoV-2 genome it is of particular consequence that there be a regular review of the target primers being used and an improvement of diagnostic assays to keep up the expected sensitivity and specificity required of diagnostic assays for COVID- 19.

\section{Limitations}

Our results are subject to inherent limitation due to small sample size of the study. Further, as we do not have genome sequences available of the SARS-CoV-2 strains described in the study, we cannot ascertain the polymorphisms present in the genomes. Further, due to the proprietary nature of the commercial assays used it would not be possible to associate sequence variations with differential amplification frequencies of the PCR tests.

\section{Abbreviations}

COVID-1: disease caused by novel coronavirus 2019; CRP: C-reactive protein; CT: Cycle Threshold; CT scan: Computerized tomography scan; D: Detected; E: Envelope; FluB: Influenza B virus; FluA: Influenza A virus; LDH: Lactate dehydrogenase; MERS-CoV: MERS coronavirus; hMPV: Human metapneumovirus; NP: Not Performed; NEG: Negative; N: Nucleocapsid; M: Membrane; OrF: open reading frame; Para (1-4): Influenza virus types para (1-4); POS: Positive; PCR: Polymerase Chain Reaction; RSV: Respiratory Synctial virus; Rhino/Entero: Human rhinovirus/enterovirus; RdRp: RNA dependent RNA polymerase;

RT-PCR: Reverse transcriptase polymerase chain reaction; SARS-CoV-2: Severe acute respiratory syndrome coronavirus 2; S: Spike; SGTF: S gene target failure; WHO: World Health Organization.

\section{Supplementary Information}

The online version contains supplementary material available at https://doi. org/10.1186/s13104-021-05722-5.

Additional file 1. Description of PCR tests.

\section{Acknowledgements}

We would like to thank the Department of Pathology and Laboratory Medicine, Aga Khan University, Karachi for administration for support in this study.

\section{Authors' contributions}

ZM identified the clinical dilemmas; SS, AN, AK, IA, ZA and NM were involved in the laboratory testing of samples; ZM and SFM reviewed the clinical evaluations; SS and ZH designed the study; ZM, SS, ZH and RH wrote the manuscript. All authors read and approved the final manuscript.

\section{Funding}

The salary of AK was supported by a Grant from Health Security Partners, USA. The work received support a University Research Council Grant, Aga Khan University.

Availability of data and materials

The data is available in the table here and raw data is available upon request.

\section{Declarations}

\section{Ethics approval and consent to participate}

This study was approved by the Ethical Review Committee, Aga Khan University as an Exemption Study based on retrospective review of clinical and laboratory records. 


\section{Consent for publication}

Not applicable.

\section{Competing interests}

The authors have no competing interests to declare.

\section{Author details}

'Department of Medicine, Aga Khan University, Karachi, Pakistan. ${ }^{2}$ Department of Pathology and Laboratory Medicine, Aga Khan University, Karachi, Pakistan. ${ }^{3}$ Department of Pediatrics and Child Health, Division of Women and Child Health, Aga Khan University, Karachi, Pakistan.

Received: 4 April 2021 Accepted: 29 July 2021

Published online: 17 August 2021

\section{References}

1. Bohn MK, et al. IFCC interim guidelines on molecular testing of SARSCoV-2 infection. Clin Chem Lab Med. 2020;58(12):1993-2000.

2. Vandenberg O, et al. Considerations for diagnostic COVID-19 tests. Nat Rev Microbiol. 2021;19(3):171-83.

3. Corman VM, et al. Detection of 2019 novel coronavirus (2019-nCoV) by real-time RT-PCR. Euro Surveill. 2020. https://doi.org/10.2807/1560-7917. ES.2020.25.3.2000045

4. Habibzadeh P, et al. Molecular diagnostic assays for COVID-19: an overview. Crit Rev Clin Lab Sci. 2021. https://doi.org/10.1080/10408363.2021. 1884640.
5. Artesi M, et al. A recurrent mutation at position 26340 of SARS-CoV-2 is associated with failure of the e gene quantitative reverse transcriptionPCR utilized in a commercial dual-target diagnostic assay. J Clin Microbiol. 2020. https://doi.org/10.1128/JCM.01598-20.

6. Kucirka LM, et al. Variation in false-negative rate of reverse transcriptase polymerase chain reaction-based SARS-CoV-2 tests by time since exposure. Ann Intern Med. 2020;173(4):262-7.

7. Wang R, et al. Mutations on COVID-19 diagnostic targets. Genomics. 2020;112(6):5204-13.

8. Bal A, et al. Two-step strategy for the identification of SARS-CoV-2 variant of concern 202012/01 and other variants with spike deletion H69-V70, France, August to December 2020. Euro Surveill. 2021. https://doi.org/10. 2807/1560-7917.ES.2021.26.3.2100008.

9. Zhao Z, et al. Moderate mutation rate in the SARS coronavirus genome and its implications. BMC Evol Biol. 2004;4:21.

10. WHO. Novel coronavirus COVID-19 therapeutic trial synopsis, in R\&D blueprint. Geneva: World Health Organization; 2020.

11. Rabaan AA, et al. Viral dynamics and real-time RT-PCR Ct values correlation with disease severity in COVID-19. Diagnostics. 2021. https://doi.org/ 10.3390/diagnostics11061091.

12. Hasan MR, et al. A novel point mutation in the N gene of SARS-CoV-2 may affect the detection of the virus by RT-qPCR. J Clin Microbiol. 2021. https://doi.org/10.1128/JCM.03278-20.

\section{Publisher's Note}

Springer Nature remains neutral with regard to jurisdictional claims in published maps and institutional affiliations.
Ready to submit your research? Choose BMC and benefit from:

- fast, convenient online submission

- thorough peer review by experienced researchers in your field

- rapid publication on acceptance

- support for research data, including large and complex data types

- gold Open Access which fosters wider collaboration and increased citations

- maximum visibility for your research: over 100M website views per year

At BMC, research is always in progress.

Learn more biomedcentral.com/submissions 